\title{
Filaggrin Genotype in Ichthyosis Vulgaris Predicts Abnormalities in Epidermal Structure and Function
}

\author{
Robert Gruber, ${ }^{*}$ Peter M. Elias, ${ }^{\dagger}$ Debra Crumrine, ${ }^{\dagger}$ \\ Tzu-Kai Lin, ${ }^{\dagger}$ Johanna M. Brandner, ${ }^{\ddagger}$ \\ Jean-Pierre Hachem, ${ }^{\S}$ Richard B. Presland, ${ }^{9 \|}$ \\ Philip Fleckman, ${ }^{\natural}$ Andreas R. Janecke, ${ }^{* *}$ \\ Aileen Sandilands, ${ }^{\dagger \dagger}$ W.H. Irwin McLean, ${ }^{\dagger \dagger}$ \\ Peter O. Fritsch, ${ }^{*}$ Michael Mildner, ${ }^{\ddagger \neq}$ \\ Erwin Tschachler, ${ }^{\ddagger \ddagger}$ and Matthias Schmuth* \\ From the Department of Dermatology, ${ }^{*}$ and Medical Genetics, \\ Molecular and Clinical Pharmacology, "** Innsbruck Medical \\ University, Innsbruck, Austria; the Dermatology Service, ${ }^{\dagger}$ \\ Veterans Affairs Medical Center and Department of Dermatology, \\ University of California, San Francisco, California; the \\ Department of Dermatology, ${ }^{\ddagger}$ University Hospital Hamburg- \\ Eppendorf, Germany; the Department of Dermatology, ${ }^{\S}$ Free \\ University of Brussels, Brussels, Belgium; the Division of \\ Dermatology, "Department of Medicine and Oral Biology," School \\ of Dentistry, University of Washington, Seattle, Washington; the \\ Epithelial Genetics Group, "t Division of Molecular Medicine, \\ Colleges of Life Sciences and Medicine, Dentistry and Nursing, \\ University of Dundee, Dundee, United Kingdom; and the \\ Department of Dermatology, ${ }^{\text {\# University of Vienna Medical }}$ \\ School, Vienna, Austria
}

Although it is widely accepted that filaggrin (FLG) deficiency contributes to an abnormal barrier function in ichthyosis vulgaris and atopic dermatitis, the pathomechanism of how FLG deficiency provokes a barrier abnormality in humans is unknown. We report here that the presence of FLG mutations in Caucasians predicts dose-dependent alterations in epidermal permeability barrier function. Although FLG is an intracellular protein, the barrier abnormality occurred solely via a paracellular route in affected stratum corneum. Abnormal barrier function correlated with alterations in keratin filament organization (perinuclear retraction), impaired loading of lamellar body contents, followed by nonuniform extracellular distribution of secreted organelle contents, and abnormalities in lamellar bilayer architecture. In addition, we observed reductions in corneodesmosome density and tight junction protein expression. Thus, FLG deficiency provokes alterations in keratinocyte architecture that influence epidermal functions localizing to the extracellular matrix.
These results clarify how $F L G$ mutations impair epidermal permeability barrier function. (Am J Patbol 2011, 178:2252-2263; DOI: 10.1016/j.ajpath.2011.01.053)

Filament aggregating protein (filaggrin, FLG) is the main component of F-type keratohyalin granules, which localize to the outer nucleated layers of the epidermis, the stratum granulosum (SG). Decreased FLG expression results in a paucity of keratohyalin granules, which is a hallmark of ichthyosis vulgaris (IV), independent of body site and season of the year. ${ }^{1-4} \mathrm{IV}$, the most prevalent disorder of cornification in humans, is characterized by the delayed, postnatal onset of generalized, fine scaling that spares the flexures, and is often associated with palmar hyperlinearity and atopic dermatitis (AD). ${ }^{5-7}$ In IV and $A D$, both nonsense and frameshift mutations have been discovered in the gene encoding FLG, which localizes to the epidermal differentiation complex on chromosome $1 q 21 .^{8-17}$ Phenotype severity appears to be subject to a dose effect, wherein heterozygous patients show a milder phenotype with reduced, but not absent, FLG, whereas IV patients with homozygous or compound heterozygous FLG mutations typically lack FLG and exhibit a more severe scaling phenotype with a greater predisposition for early development and more severe AD. ${ }^{8-12,18}$

Although decreased FLG is widely postulated to account for the epidermal permeability barrier abnormality in IV and AD, ${ }^{19-22}$ the cellular pathogenesis of the barrier defect is not known. It is difficult to assess how FLG deficiency leads to the barrier abnormality in $A D$, because Th2-dominant inflammation can secondarily com-

Supported by MFF grants No. 71 and 153, NIH grants AR019098 and Al059311, the Medical Research Service, Department of Veterans Affairs, San Francisco, CA, and EU-FP7 COST Action BM0903.

Accepted for publication January 25, 2011.

W.H.I.M. has filed patents relating to genetic testing and therapy development aimed at the FLG gene.

Supplemental material for this article can be found at http://ajp. amjpathol.org and at doi: 10.1016/j.ajpath.2011.01.053.

Address reprint requests to Matthias Schmuth, M.D., Department of Dermatology, Anichstraße 35, 6020 Innsbruck, Austria. E-mail: matthias. schmuth@i-med.ac.at. 
promise barrier function by multiple mechanisms, ${ }^{23}$ including an acquired reduction in FLG. ${ }^{24,25}$ Thus, whether FLG deficiency suffices to provoke a barrier abnormality, and how such an abnormality might occur, remain unknown. The possibility that FLG deficiency suffices to provoke a barrier abnormality is supported by recent studies in flaky tail (ft/ft) mice, which demonstrate abnormalities in barrier function in association with an absence of FLG. ${ }^{26-29}$

In normal epidermis, the permeability barrier localizes to the stratum corneum (SC) matrix, which is organized into neutral lipid-enriched, extracellular lamellar bilayers. This hydrophobic extracellular matrix, together with the cohesive properties of specialized intercellular junctions in SC and SG; ie, corneodesmosomes and tight junctions (TJs), provides the epidermis with a formidable barrier to the outward loss of water and electrolytes, while also blocking transcutaneous entry of exogenous xenobiotes. ${ }^{24,30-33}$ Yet, FLG is an intracellular protein, and how deficiency of this structural protein could alter a key extracellular function, ie, permeability barrier homeostasis, is not immediately obvious. One potential mechanism could be through an altered corneocyte scaffold. As shown in both transglutaminase 1-deficient lamellar ichthyosis, ${ }^{34}$ and in loricrin keratoderma, ${ }^{35}$ a defective cornified envelope (CE) leads to disorganization of extracellular lamellar bilayers. Alternatively, dominant-negative disruption of the cytoskeleton, as occurs with mutations in either keratin 1 or 10 in epidermolytic ichthyosis (epidermolytic hyperkeratosis), blocks lamellar body (LB) secretion, also resulting in a downstream, paracellular permeability barrier defect. ${ }^{36}$ Since FLG peptides normally associate with both the $\mathrm{CE}^{37-39}$ and keratin filaments, ${ }^{40}$ FLG deficiency could compromise permeability barrier function by either mechanism, by both mechanisms, or by a mechanism that is unique to IV. Although in the pre-genotype era, barrier function was shown to be moderately abnormal in IV and AD patients, ${ }^{41-45}$ this has not been assessed in genotyped, FLG-deficient IV patients, and there is little evidence for the mechanisms of a potential barrier defect. Therefore, we asked here whether FLG deficiency provokes allele-, and dose-dependent changes in epidermal function, and set out to clarify the subcellular basis for such abnormalities.

\section{Materials and Methods}

\section{Human Subjects}

The study was approved by the institutional review boards of the Innsbruck Medical University, Innsbruck; the University of California, San Francisco; and the University of Washington, Seattle; and complied with the Declaration of Helsinki Principles. Subjects included patients with IV (eight double allele and 11 single allele), defined as generalized fine scaling involving the extensor surfaces of the extremities, palmoplantar hyperlinearity, and/or keratosis pilaris. As controls, we included 20 individuals lacking scaling or any other inflammatory skin symptoms (see Supplemental Table S1 at http://ajp. amjpathol.org). Specifically excluded were: i) patients with an IV phenotype, but none of the common FLG mutations; ii) control subjects with $A D$, allergic rhinitis, or asthma; iii) individuals with thyroid disease; or iv) individuals receiving systemic immunosuppressives or systemic retinoids within 6 months before enrollment.

\section{Genotyping}

Genomic DNA was extracted from peripheral blood or saliva (ORAgene DNA Self-Collection Kit; DNA Genotek, Kanata, ON, Canada) using the GenoM48 automated extractor (Qiagen, Vienna, Austria). FLG variants R501X, 2282del4, and R2447X were screened by restriction enzyme digestion of PCR products, FLG variants 3702delG and 6867 delAG by sizing of fluorescently labeled PCR products as described previously. ${ }^{9,12}$ For 2282del4 screening, we used an allele-specific PCR, amplifying a short fragment of $158 \mathrm{bp}$ with high genotype completion rates. Genomic DNA was amplified by using Promega PCR buffer (Promega, Madison, WI), Promega Taq polymerase mix, and allele-specific primers: 5'-AGAAGACTCAGACACACATTG-3' (forward), 5'-GGGAGGACTCAGACTGTTT-3' (reverse). Amplification conditions were as follows: $95^{\circ} \mathrm{C}$ for 3 minutes; 35 cycles of $95^{\circ} \mathrm{C}$ for $20 \mathrm{~s}$, $60^{\circ} \mathrm{C}$ for $30 \mathrm{~s}, 72^{\circ} \mathrm{C}$ for $40 \mathrm{~s}$; a final extension step at $72^{\circ} \mathrm{C}$ for 5 minutes. A fragment of $207 \mathrm{bp}$ was amplified from an unrelated chromosomal region in each reaction to control for PCR success, using forward primer 5'-ATTCTTTGTCCCTGGCAGT- $3^{\prime}$ and reverse primer $5^{\prime}$-GACAGTTCCCAAATGACAAGT- $3^{\prime}$. In patients showing the 2282del4 mutation, a PCR for differentiation between homozygous and heterozygous followed using the same conditions, reverse primer, and control fragment primers as described above, and the forward primer 5'-AGAAGACTCAGACACACAGTTAG-3'. PCR products and digests were resolved on $2 \%$ agarose gels.

\section{Functional Measurements}

Functional measurements were performed in 32 study subjects, eight with two FLG mutations (-/-), 11 with 1 FLG mutation (+/-), and 13 wild-type controls (see Supplemental Table S1 at $h$ ttp://ajp.amjpathol.org). The subjects were not allowed to use emollients, or any other topical formulations and medications on the test sites for at least 3 days before and during the experiments. Surface $\mathrm{pH}$ was measured using a Skin-pH-Meter (PH900; Courage \& Khazaka, Köln, Germany), equipped with a flat glass electrode (Mettler-Toledo, Giessen, Germany). SC hydration was assessed as change in electrical capacitance (absolute units) using a Corneometer (CM 825; Courage \& Khazaka). Transepidermal water loss (TEWL) was measured using an Evaporimeter (Servomed, Stockholm, Sweden), and measurements were taken on the lower forearm in accordance with published guidelines. ${ }^{46-48}$ Environment-related variables at the time of the study were: ambient air temperature $19.5^{\circ} \mathrm{C}$ to $24^{\circ} \mathrm{C}$; skin surface temperature $30.4^{\circ} \mathrm{C}$ to $32.5^{\circ} \mathrm{C}$, ambient air humidity $31 \%$ to $45 \%$, and water vapor pressure 4.7 to $10.9 \mathrm{~mm} \mathrm{Hg}$. The study subjects underwent at least a 
15-minute pre-assessment rest period, and measurements were taken after equilibration of the probe on the skin surface. Readings were made when TEWL levels had stabilized, 30 to 120 seconds after applying the probe. The values were expressed as grams per square meter per hour. TEWL was measured both under basal conditions, as well as following acute barrier disruption by repeated cellophane tape stripping (to TEWL $\sim$ threefold basal value). Barrier recovery kinetics were assessed by measuring TEWL at 3 and 6 hours after acute disruption. For calculation of the percentage change in TEWL, the following formula was used: [(TEWL stripped area at indicated time/TEWL control area at indicated time)/(TEWL stripped area before stripping/TEWL control area before stripping) -1$] \times 100 \%$.

\section{Assessment of CE Fragility and SC Cohesion}

Corneocytes were isolated by scraping the skin with a scalpel blade from the three FLG genotype groups (see Supplemental Table S1 at http://ajp.amjpathol.org) using the method of Määttä et $\mathrm{al}^{4}{ }^{49}$ with modifications as follows: Isolated squames were placed in $2 \%$ SDS, 5 $\mathrm{mmol} / \mathrm{L}$ EDTA, $10 \mathrm{mmol} / \mathrm{L}$ dithiothreitol in $20 \mathrm{mmol} / \mathrm{L}$ Tris$\mathrm{HCl}$, and boiled for 10 minutes. After centrifuging $(2000 \times$ $g$ for 5 minutes), corneocyte suspensions were assessed by light microscopy in the Nomarsky mode. ${ }^{50}$ To assess corneocyte fragility under stressed conditions, the pellet was resuspended in $2 \%$ SDS and subjected to ultrasound (U200S control, amplitude 20\%, cycle 0.1; IKA Labortechnik, Staufen, Germany ). SC cohesion was assessed as protein removed per D-Squame (CuDerm Corporation, Dallas, TX), applied sequentially to the test area for about 3 seconds, removed with a forceps, and stored in a glass scintillation vial at $4^{\circ} \mathrm{C}$. The amount of protein removed per D-Squame was measured by a modification of the method of Dreher et al, ${ }^{51}$ using the Bio-Rad Protein Assay Kit (Bio-Rad, Vienna, Austria). Lyophilized, bovine gamma globulin was used as the standard. Each tape was incubated with $1 \mathrm{~mL}$ of $1 \mathrm{~mol} / \mathrm{L} \mathrm{NaOH}$ for 1 hour at $37^{\circ} \mathrm{C}$, neutralized with $\mathrm{HCl}$ in the scintillation vials. Subsequently, $0.2 \mathrm{~mL}$ of this solution was incubated in $0.6-\mathrm{mL}$ distilled water plus $0.2 \mathrm{~mL}$ of the Bio-Rad protein dye for 5 minutes in borosilicate tubes. After incubation, the reagents were transferred to polystyrene cuvettes, and absorption was measured with a spectrophotometer (Ultrospec 3300 pro; AmershamBiosciences/GE Healthcare, Piscataway, NJ) at $595 \mathrm{~nm}$. An empty D-Squame tape as well as distilled water incubated with the Bio-Rad dye served as negative controls. The amount of calculated protein was then normalized to skin surface area $\left(\mu \mathrm{g} / \mathrm{cm}^{2}\right)$.

\section{Light Microscopy and IHC}

Four-millimeter punch biopsies were taken from the skin of 11 individuals with FLG deficiency and from seven controls without FLG mutations (see Supplemental Table S1 at http://ajp.amjpathol.org). Specimens were fixed in $4 \%$ formaldehyde, embedded in paraffin, sectioned (6 $\mu \mathrm{m})$, and then stained with hematoxylin and eosin. For
$I H C$, paraffin-embedded sections were stained with a monoclonal mouse anti-human FLG antibody (Novocastra Laboratories Ltd, Newcastle upon Tyne, UK) in a working dilution of 1:50, a polyclonal rabbit anti-human loricrin antibody (Abcam, Cambridge, UK) in a working dilution of 1:100, a monoclonal mouse anti-human cytokeratin 10 antibody (Dako, Glostrup, Denmark) in a working dilution of 1:100, and a monoclonal rabbit antibody against Ki-67 (Ventana Medical Systems S.A., France) in a working dilution of 1:50, respectively, using the automated preparation system BenchMark XT (Ventana Medical Systems) and the high-temperature antigen unmasking technique according to the manufacturer's instructions (pretreatment with sodium/citrate buffer, incubation time 16 minutes, temperature $37^{\circ} \mathrm{C}$ ). Images were generated using the laser optic system (ProgRes C10plus; Jenoptik, Jena, Germany) and PicEd Cora software. Proliferation index was assessed as percentage of Ki-67-positive cells in fields of 400 magnification in age-, sex-, and body-site-matched biopsies. For tight junction proteins Occ1 and ZO-1, we pretreated sections for antigen retrieval by microwave oven heating $(4 \times 5$ minutes; $600 \mathrm{~W}$ ) in TEC buffer ( $\mathrm{pH} 7.8)$, followed by mild trypsinization with $0.001 \%$ trypsin for 10 minutes at $37^{\circ} \mathrm{C}$. DAKO Cytomation Protein Block was used to block unspecific binding sites and change surface tension. Primary antibodies were applied to the sections overnight at $4^{\circ} \mathrm{C}$ (Occl pAb, 71-1500; Zymed/Invitrogen, Carlsbad, CA) 1:200, ZO-1 (pAb, 61-7300, Zymed/Invitrogen) 1:100). The samples were subsequently washed for $3 \times$ 3 minutes in TBST. Afterward, Alexa 594-coupled (1:1250 in PBS, specific for rabbit) secondary antibodies (Molecular Probes Europe BV, Leiden, the Netherlands) were applied for 30 minutes at room temperature. Nuclei were stained by a subsequent incubation with DAPI (1:5000 in PBS). For negative controls, isotype-specific antibodies were used.

\section{Organotypic Cultures}

Normal human dermal fibroblasts (Lonza, Basel, Switzerland) and normal human epidermal keratinocytes (Lonza) were cultured as described previously. ${ }^{52}$ Stealth small interfering RNAs (siRNAs) specific for FLG and a scrambled control were obtained from Invitrogen. ${ }^{53}$ siRNA transfection and preparation of organotypic skin cultures were performed as described previously. ${ }^{52}$ Briefly, thirdpassage keratinocytes were transfected using Lipofectamine 2000 (Invitrogen). Five milliliters of OPTI-MEM medium (Gibco/Invitrogen) was mixed with 50- $\mu \mathrm{L}$ Lipofectamine 2000 and $130 \mu \mathrm{L}$ of a $20 \mu \mathrm{mol} / \mathrm{L}$ siRNA solution. After incubation at room temperature for 30 minutes, the solution was added to $20 \mathrm{~mL}$ of keratinocyte growth medium (Lonza) transferred to the keratinocyte cultures and incubated for 24 hours. To generate the organotypic skin, $2.5 \mathrm{~mL}$ of collagen type I (Vitrogen 100; Collagen Corporation, Palo Alto, CA) containing $2.5 \times 10^{5}$ fibroblasts, balanced by Hank's buffered salt solution (HBSS) (Gibco/Invitrogen), was poured into each cell-culture insert (3- $\mu \mathrm{m}$ pore size; BD Bioscience, Bedford, MA) and 
allowed to gel for 2 hours at $37^{\circ} \mathrm{C}$ in a humidified atmosphere. The gels were then equilibrated with keratinocyte growth medium for 2 hours, and $1.5 \times 10^{6}$ keratinocytes transfected with the respective siRNAs were seeded onto each collagen gel. After overnight incubation at $37^{\circ} \mathrm{C}$, the medium was removed from both the inserts and external wells, and $10 \mathrm{~mL}$ of keratinocyte-defined medium, consisting of keratinocyte growth medium without bovine pituitary extract and supplemented with $1.3 \mathrm{mmol} / \mathrm{L}$ calcium (Sigma, Vienna, Austria), $10 \mu \mathrm{g} / \mathrm{mL}$ transferrin (Sigma), $50 \mu \mathrm{g} / \mathrm{mL}$ ascorbic acid (Sigma), and $0.1 \%$ bovine serum albumin (Sigma) added to each external well. Keratinocytes were allowed to form a multilayered epidermis for 7 days, and medium was changed every second day.

\section{Electron Microscopy}

The ultrastructure of the skin biopsy specimen was analyzed in nine FLG-deficient and seven wild-type subjects (see Supplemental Table S2 at http://ajp.amjpathol.org). We used an algorithmic sequence similar to that previously applied to Harlequin ichthyosis, ${ }^{54}$ epidermolytic ichthyosis, ${ }^{36}$ autosomal recessive (lamellar) ichthyosis, ${ }^{34}$ Ioricrin keratoderma, ${ }^{35}$ Netherton syndrome, ${ }^{55}$ and neutral lipid storage disease. ${ }^{56}$

Skin samples, derived from punch biopsies, were minced to $<0.5 \mathrm{~mm}^{3}$ fragments, rinsed three times in 0.1 $\mathrm{mol} / \mathrm{L}$ cacodylate buffer, and pre-fixed in half-strength Karnovsky's fixative, followed by postfixation in reduced $1 \%$ osmium tetroxide $\left(\mathrm{OsO}_{4}\right)$ containing $1.5 \%$ ferrocyanide or in $0.2 \%$ ruthenium tetroxide $\left(\mathrm{RuO}_{4}\right) \cdot{ }^{57-59}$ Selected samples were immersed for 2 hours in absolute pyridine for visualization of the cornified lipid envelope, followed by $\mathrm{OsO}_{4}$ postfixation, as described previously. ${ }^{54,60}$ The combination of osmium $\left(\mathrm{OsO}_{4}\right)$ and ruthenium tetroxide $\left(\mathrm{RuO}_{4}\right)$ postfixation protocols with pyridine pretreatment allowed us to assess the CE scaffold in relation to the extracellular lamellar bilayer system, as described previously. ${ }^{54,61}$ After staining with $2 \%$ aqueous uranyl acetate and embedding in Epon epoxy, ultrathin sections (600A) were assessed using a Zeiss 10A electron microscope (Oberkochen, Germany), operated at $60 \mathrm{kV}$.

\section{Assessment of Corneocyte Morphology}

The number of SC layers was counted at $\times 3.5$ to $\times 10$ magnification. CE thickness was quantitated with an image analyzer, attached to the electron microscope camera, in the lowest SC layer (first SC layer above the SG-SC junction) versus outermost SC layer by an unbiased observer who did 30 measurements taken from five images at $\times 125$ magnification. The length of corneodesmosomes was measured between the first and second SC layer above the SG-SC junction at $\times 25$ and expressed as corneodesmosome length/total CE length.

\section{Assessment of Permeability Pathway by Lanthanum Perfusion}

Using the water-soluble, low molecular weight tracer colloidal lanthanum, ${ }^{62}$ we determined whether there was increased permeability due to leaky corneocytes, resulting in increased transcellular water movement (fragility), or an abnormality due to enhanced extracellular permeability (normal SC excludes lanthanum movement). Skin fragments prepared as described above were immersed in $4 \%$ lanthanum nitrate in $0.05 \mathrm{~mol} / \mathrm{L}$ Tris buffer $(\mathrm{pH} \mathrm{7.4)}$ containing $2 \%$ glutaraldehyde and $1 \%$ paraformaldehyde for 1 hour at room temperature. ${ }^{36,63,64}$ After lanthanum perfusion, the samples were washed and processed for electron microscopy, as described above.

\section{Lamellar Body Morphology, Secretion, and Extracellular Bilayer Structure}

We assessed LB and the extent of LB secretion to determine whether FLG deficiency interferes with secretion of LB contents. LB numbers were determined in granular cells two to three layers below the SG-SC junction by counting LBs at $\times 16$ magnification using a calibrated grid. To assess the LB secretory system, the following criteria were assessed: i) amount of accumulated lipid material at the SG-SC junction ${ }^{65}$; ii) presence of "entombed" LB within the corneocyte cytosol' 6 ; and iii) extent of extracellular delivery versus corneocyte retention of a lipid hydrolase (acid lipase), which is concentrated in $\mathrm{LB}$ and normally secreted and segregated in toto within the SC interstices. ${ }^{64,65,67}$ For quantification of LB secretion, areas of secretion at the SG-SC junction were measured and correlated with the length of the bottom surface of the first SC layer on 10 random images at $16 \mathrm{~K}$ magnification. For lipid hydrolase visualization, aldehydeprefixed samples were microwave incubated with $0.2 \%$ Tween 85-containing substrate (+/- lipase inhibitor, tetrahydrolipstatin, $200 \mu \mathrm{mol} / \mathrm{L}$ ), a lead-capture cytochemical method that depicts the localization of acidic and neutral lipases. ${ }^{59}$ Samples were then postfixed in $\mathrm{OsO}_{4}$ and processed as above. Finally, on $\mathrm{RuO}_{4}$ postfixed tissue, the maturation and supramolecular organization of extracellular lamellar bilayer quantities were determined.

\section{Statistics}

Numerical results were analyzed using the Mann-Whitney rank sum test to compare individual groups and the Kruskal-Wallis test for across-group significance. Analyses were conducted using the Prism5 software package (GraphPad, San Diego, CA). A value of $P<0.05$ was considered statistically significant. The graphs depict the results as mean \pm SEM. For the analysis of ultrastructure, two observers were blinded to the case-control status of the study subjects. 
Table 1. Demographic Characteristics

\begin{tabular}{|c|c|c|c|c|c|c|}
\hline & \multicolumn{3}{|c|}{ Functional studies } & \multicolumn{3}{|c|}{ Morphological studies* } \\
\hline & $\begin{array}{c}2 \text { FLG mutations } \\
n=8\end{array}$ & $\begin{array}{c}1 \text { FLG mutation } \\
n=11\end{array}$ & $\begin{array}{c}\text { No FLG mutation } \\
n=13\end{array}$ & $\begin{array}{c}2 \text { FLG mutations } \\
n=6\end{array}$ & $\begin{array}{c}1 \text { FLG mutation } \\
n=3\end{array}$ & $\begin{array}{c}\text { No FLG mutation } \\
n=7\end{array}$ \\
\hline Female & 2 & 7 & 4 & 1 & 1 & 1 \\
\hline Male & 6 & 4 & 9 & 5 & 2 & 6 \\
\hline Age (range) & $57(21-88)$ & $40(26-69)$ & $55(22-91)$ & $52(21-68)$ & $49(26-69)$ & $51(22-81)$ \\
\hline
\end{tabular}

*Including a subgroup of individuals also assessed in functional studies.

\section{Results}

\section{Loss of FLG Results in Distinctive Corneocyte Abnormalities and Altered Epidermal \\ Homeostasis}

We studied here a cohort of patients of self-reported European ancestry with IV (Table 1). Among this study subgroup, R501X was the most common FLG mutation, followed in frequency by R2447X, 2282del4, and 6867deIAG (see Supplemental Table S1 at http://ajp.amjpathol. org). Double-allele subjects were compound heterozygote for R501X/R2447X ( $n=4)$, R501X/2282del4 ( $n=$ $2)$, R501X/6867delAG $(n=1)$, and homozygote for 2282del4/2282del4 $(n=1)$. FLG expression was assessed by histology, IHC, and by electron microscopy, which displayed an absence to near-absence of F-type keratohyalin granules in double-allele patients, with residual granules and FLG expression in single-allele subjects (see Supplemental Figure S1A at http://ajp. amjpathol.org).

Reduced FLG correlated with a previously undescribed, ultrastructural feature; ie, the distinctive, perinuclear "halos" resulting from retraction of keratin intermediate filaments (Figure 1). Reduction or loss of FLG correlated with an increased number of SC cell layers (Figure 2A; see also Supplemental Figure S1 at $h$ ttp://ajp. amjpathol.org) and an increased number of suprabasal, Ki-67-positive cells in double-allele patients (see Supplemental Figure S1D at http://ajp.amjpathol.org). Finally, with the exception of reduced FLG, other differentiation markers, such as loricrin and keratin 10, did not differ in FLG-deficient versus control subjects (see Supplemental Figure S1, B and C, at http://ajp.amjpathol.org). Together, these results demonstrate that FLG mutations result in a characteristic cytoskeletal abnormality, as well as altered epidermal homeostasis.

\section{Defective Corneocyte Integrity in FLG-Deficient SC}

Defective corneocyte structure could compromise epidermal function in IV. In both single- and double-allele IV versus control subjects, the corneocyte cytosol appeared normal on electron microscopy (Figure 3D; see also Supplemental Figure S2A at http://ajp.amjpathol.org). Yet, CE dimensions, measured in coded, randomized electron micrographs, moderately differed in both single- and double-allele FLG-deficient versus wild-type corneo- cytes. In contrast, the morphology of the corneocytebound lipid envelope, which consists predominantly of long-chain, $\omega$-hydroxy ceramides that are covalently attached to the outer surface of the CE, appeared normal in FLG-deficient patients (see Supplemental Figure S2A at http://ajp.amjpathol.org). Thinning of CEs in IV corneocytes correlated with a moderate, gene dose-dependent impairment in corneocyte integrity (Figure 3), which was more subtle than the abnormality previously described for TG1-deficient, autosomal recessive lamellar ichthyosis. ${ }^{68}$ Specifically, although control corneocytes were not disrupted by detergent/heat treatment, a subgroup of corneocytes from IV subjects displayed ragged, fragile outlines after detergent and heat $\left(2 \% \mathrm{SDS}, 80^{\circ} \mathrm{C}\right)$ treatment, abnormalities that were most obvious in patients with two FLG mutations (Figure 3A). Moreover, the time to corneocyte disruption on ultrasound was significantly decreased in double-allele IV as compared to wild type; however differences were not significant between singleallele IV and controls (Figure 3B). After 90 seconds of ultrasound exposure, similar degrees of destruction were
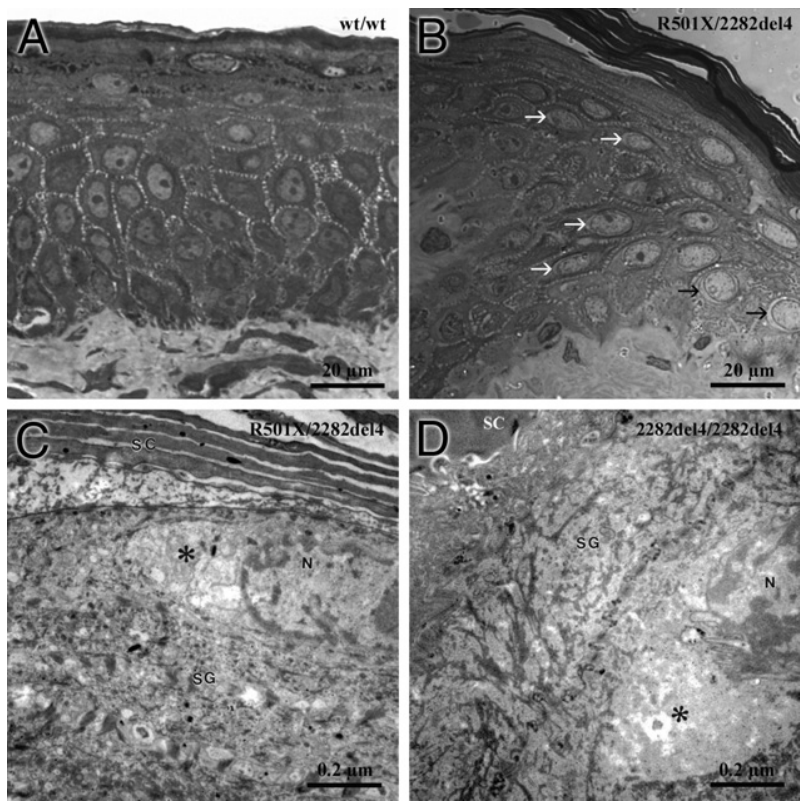

Figure 1. Cytoskeletal abnormalities in IV. As compared to control subjects (wt/wt) (A), intermediate filament retractions and reductions in F-type keratohyalin are visible in keratinocytes of FLG-deficient epidermis (B-D). Abnormalities shown are from a FLG compound heterozygote (B and C) and a homozygote (D) subject. Arrows and asterisks depict perinuclear keratin intermediate filament retraction. N, nucleus; SC, stratum corneum; SG, stratum granulosum. A and B: Toluidine blue staining. Scale bar $=20 \mu \mathrm{m}$. C and D: Osmium tetroxide postfixation. Scale bars $=0.2 \mu \mathrm{m}$. 
A

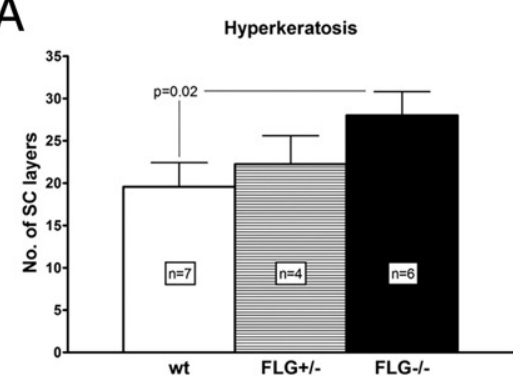

D

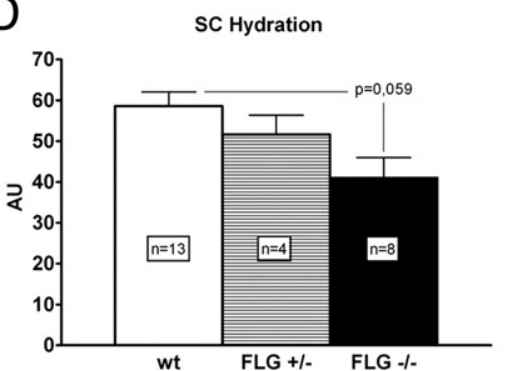

B

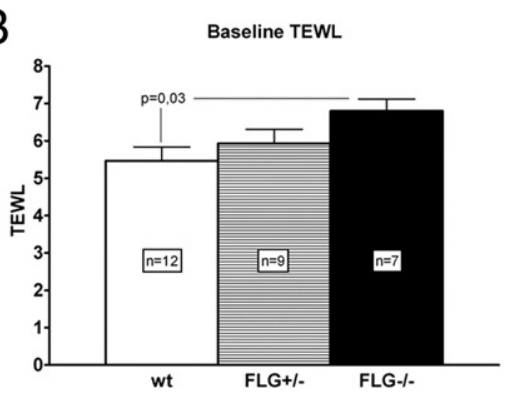

E

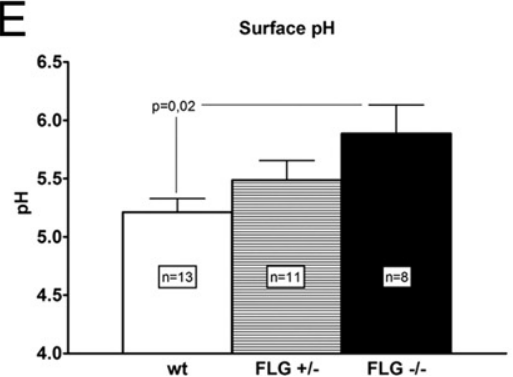

C

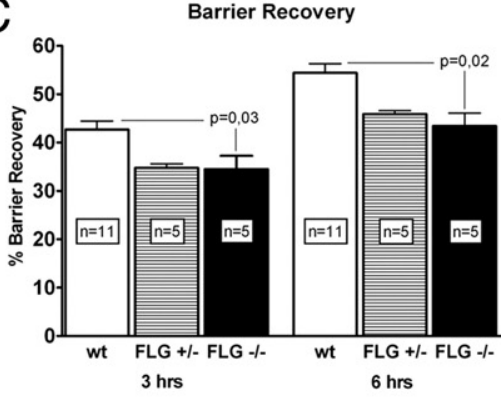

F

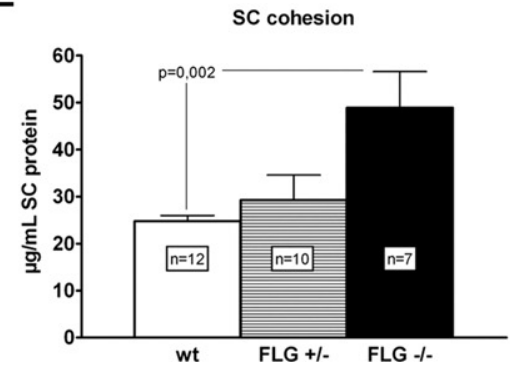

Figure 2. Filaggrin genotype-dependent changes in epidermal function in IV. A: Hyperkeratosis assessed as the number of SC layers in coded, randomized, H\&E-stained sections. wt, wild type. B: Basal barrier function, assessed as transepidermal water loss (TEWL) with an evaporimeter. C: Barrier recovery kinetics, expressed as percentage change in barrier function over time after sequential tape strippings (initial TEWL $\geq$ threefold of basal level). D: SC hydration, assessed as electrical conductance with a corneometer. AU, arbitrary units. E: Surface pH, assessed with a flat-surface probe. F: Intercellular cohesion, assessed as application of successive tape strips followed by quantitation of total protein.

observed in FLG-deficient and wild-type individuals (Figure 3C). Thus, despite normal-appearing corneocytes, FLG-deficient corneocytes display gene dose-dependent alterations in CE structure that result in reduced corneocyte integrity.

\section{FLG Dose-Dependent Abnormalities in Epidermal Permeability Barrier Function}

As noted above, most prior assessments of barrier function in IV predate the era of FLG mutation analysis, and an undetermined number of these patients also could have had co-existent AD. Therefore, to ascertain the relationship of FLG mutation status to barrier function, we next assessed basal permeability barrier function over two separate, non-sun-exposed body sites in IV and control subjects; ie, distal volar forearm and lateral lower leg. Although single-allele subjects did not display abnormalities in basal barrier function, assessed as transepidermal water loss levels, TEWL levels were elevated significantly in double-allele subjects (Figure 2B). Since basal TEWL measurements often do not suffice to identify underlying functional abnormalities, we next compared the kinetics of permeability barrier recovery after acute barrier disruption by repeated tape stripping in FLG-deficient and control subjects (in these studies, tape stripping was continued until TEWL values were increased to levels $\geq$ threefold over basal levels). The kinetics of barrier recovery then were assessed as percentage change from time 0 at 3 and 6 hours after acute disruption. As shown in Figure 2C, barrier recovery was delayed, even in single-allele subjects. Together, these results show that FLG deficiency alone suffices to alter permeability barrier function in IV.

\section{Abnormal Paracellular Permeability in IV and in FLG-Deficient Organotypic Cultures}

In all of the inherited disorders of corneocyte proteins to date, increased permeability has unexpectedly occurred via a paracellular, rather than transcellular pathway, due to abnormalities in either corneocyte scaffold function or cytoskeletal disruption of lamellar body secretions. ${ }^{69}$ Therefore, we next assessed the perfusion pathway taken by a water-soluble, electron-dense tracer, lanthanum nitrate, in IV and control subjects. Lanthanum tracer normally was excluded from both the corneocyte cytosol and the extracellular matrix in control subjects (Figure 4A). In contrast, despite the abnormalities in CE structure and integrity described above, tracer permeated into and through the SC in both single- and double-allele FLGdeficient subjects, with passage restricted to extracellular domains (Figure 4B), indicating the presence of a paracellular permeability abnormality in IV.

To further establish that FLG deficiency alone suffices to provoke a barrier abnormality, we next assessed lanthanum perfusion in organotypic human skin, generated from keratinocytes transfected with two different small interfering ribonucleic acids, or a scrambled ribonucleic acid control. ${ }^{53}$ The knock-down efficiency was $\geq 90 \%$ for both siRNAs (data not shown). Whereas control cultures again excluded tracer from the SC (Figure 4C), FLGdeficient cultures displayed lanthanum movement into and across the SC, but again solely via the extracellular (paracellular) pathway (Figure 4, D and E). Accordingly, organotypic cultures, prepared with keratinocytes from single- and double-allele IV subjects, also showed a paracellular permeability barrier abnormality (data not shown). Together, these results demonstrate that IV con- 

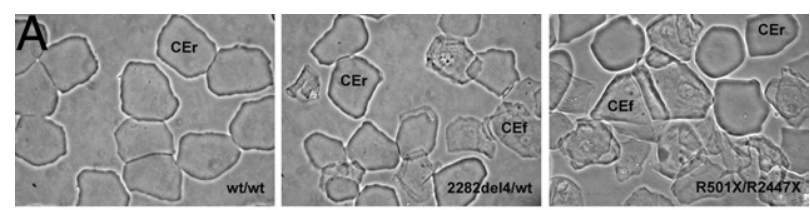

B

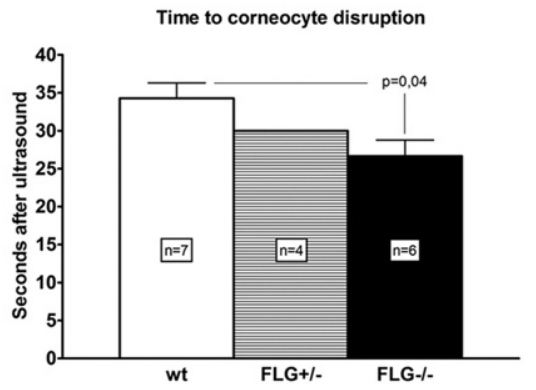

C
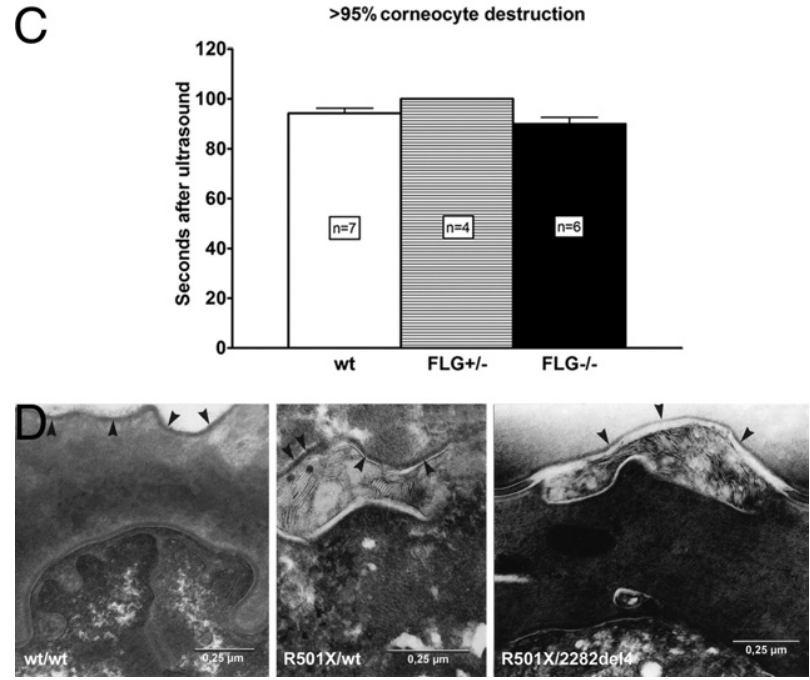

Figure 3. Altered corneocyte integrity in FLG-deficient IV. A: Higher percentages of fragile corneocytes (CEf) in heterozygotes and homozygotes compared to rigid corneocytes (CEr) in wild-type (wt) individuals. Corneocytes were treated with detergent $(2 \%$ SDS $)$ and heat $\left(80^{\circ} \mathrm{C}\right)$, and assessed by phase microscopy. Original magnification, $\times 100$. B: The time to disruption of sonicated corneocytes is significantly decreased in double-allele IV. C: Similar degrees of destruction after 90 seconds of ultrasound exposure are observed in FLG-deficient and wild-type subjects. D: Normal-appearing corneocyte envelopes (arrowheads) in IV. Ruthenium tetroxide postfixation. Scale bars $=0.25 \mu \mathrm{m}$.

fers a paracellular permeability barrier abnormality due specifically to FLG deficiency.

\section{Cellular Basis for the Paracellular Permeability Barrier Abnormality in N}

\section{Abnormal Extracellular Lamellar Bilayer Maturation and Organization}

To identify abnormalities that could account for altered paracellular permeability in IV, we next examined the supramolecular organization of lamellar bilayers, using ruthenium tetroxide $\left(\mathrm{RuO}_{4}\right)$ postfixation (Figure 5, A-E). In FLG wild-type control SC, mature (processed) lamellar bilayers replace newly secreted membrane structures one cell layer above the SG-SC interface (Figure 5, A and C). Although the overall quantities of lamellar bilayers were comparable in control subjects and IV patients (Figure 5, A and B), in the latter, lamellar bilayer organization was disrupted by foci of nonlamellar, electron-dense material in the mid-to-upper SC (Figure 5B), which was not seen in wild-type SC (Figure 5C). Moreover, in most FLG double-allele cases, the SC displayed incompletely processed lamellar material, interspersed with mature lamellar bilayers, several cell layers above the SG-SC interface (Figure 5, D and E; see also Supplemental Table S2 at http://ajp.amjpathol.org). Together, these results show that the paracellular barrier abnormality in IV can be attributed to both abnormal organization and delayed maturation of extracellular lamellar bilayers.

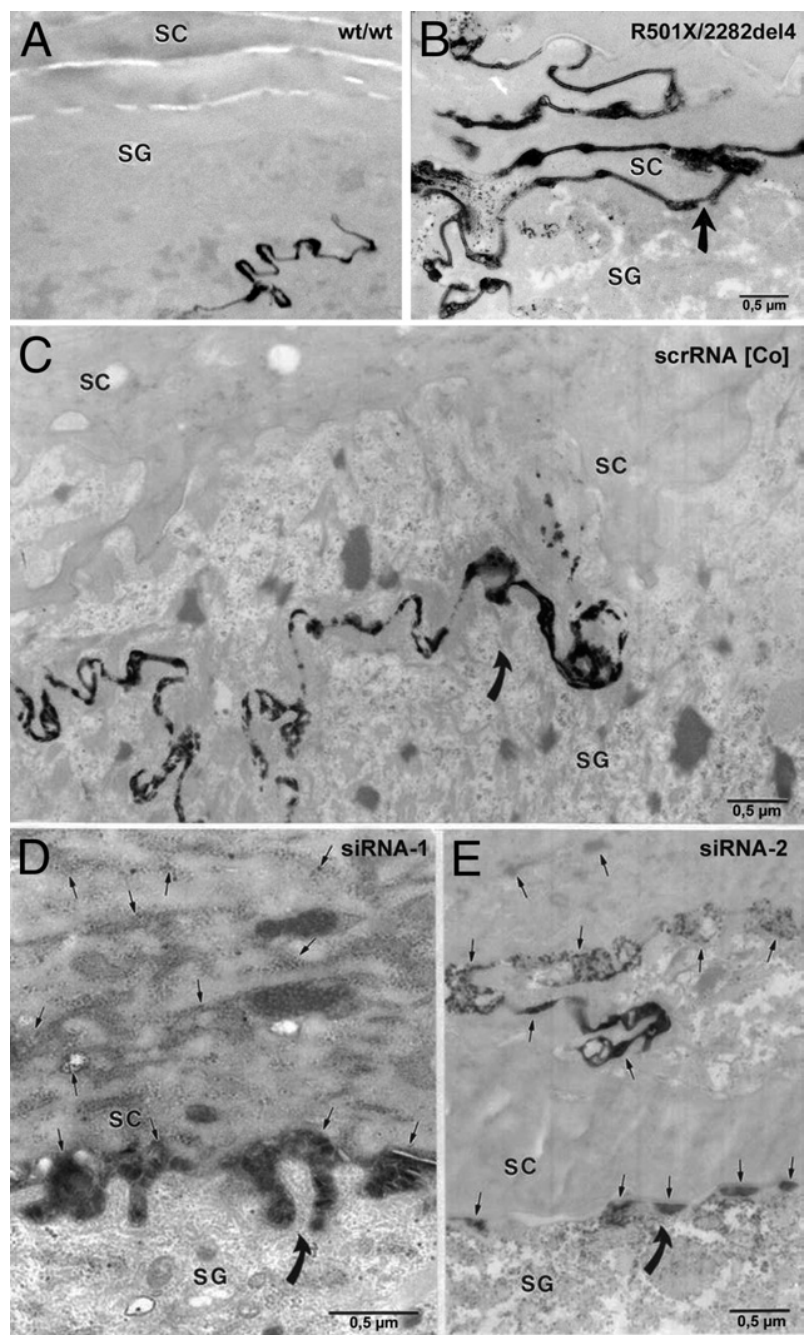

Figure 4. Paracellular barrier defect in IV and FLG-deficient, organotypic keratinocyte cultures. A: Biopsies were incubated ex vivo with a watersoluble, low molecular weight tracer, colloidal lanthanum nitrate. Lanthanum tracer is excluded from both the corneocyte cytosol and the extracellular matrix of the SC in control subjects (wt/wt). B: Tracer breaches stratum granulosum (SG)-SC interface in both single-allele (not shown) and doubleallele patients and crosses SC by a paracellular route. C-E: Filaggrin expression in organotypic skin cultures was reduced by $>90 \%$ with both siRNAs before incubation with the lanthanum tracer. C: Stop of tracer perfusion at the SG-SC interface in keratinocytes transfected with a scrambled (scr)RNA. D and E: FLG-deficient cultures (two different siRNAs) display lanthanum movement into and across the SC via the paracellular pathway. Curved arrows (B-E) indicate (outward) direction of tracer movement. Small arrows (D and E) mark colloidal lanthanum nitrate in the extracellular space. Osmium tetroxide postfixation. Scale bars $=0.5 \mu \mathrm{m}$. 

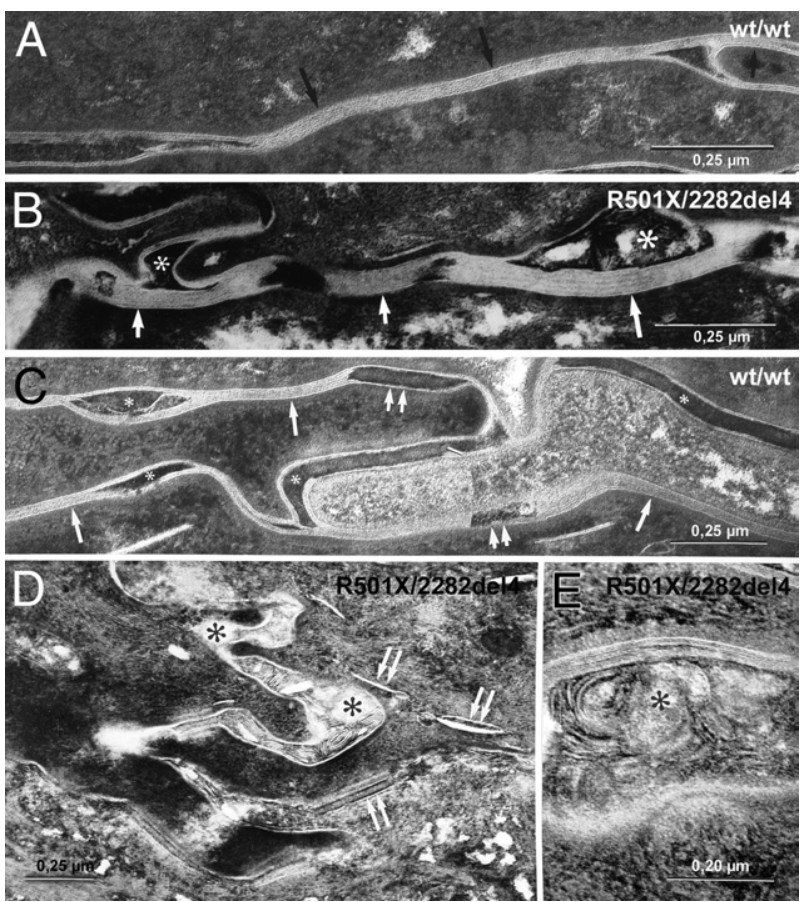

Figure 5. Abnormal extracellular lamellar bilayer organization and maturation in IV. A and C: Normal lamellar bilayers (arrows), corneodesmosomes (double-arrows), and corneodesmosome-derived lacunae (asterisks) in two different wild-type (wt) controls. B and D-E: Lamellar bilayers, corneodesmosomes, and corneodesmosome-derived lacunae in two different, double-allele IV subjects. B: Normal numbers of bilayers (arrows), but disruption of membrane arrays by nonlamellar domains (asterisks). D and E: Delayed maturation, ie, transformation of secreted lamellar body contents into bilayers above the SG-SC interface (asterisks). Note that corneodesmosome structure (double arrows) appears normal. Ruthenium tetroxide postfixation. Scale bars $0.25 \mu \mathrm{m}(\mathbf{A}-\mathbf{D}) ; 0.2 \mu \mathrm{m}(\mathbf{E})$.

\section{Decreased Lamellar Body Contents Correlate with Abnormal Lamellar Bilayer Architecture in FLG-Deficient SC}

Because extracellular lamellar bilayers were disorganized and displayed delayed maturation, we next assessed whether lamellar body density, contents, or secretion are impaired in IV. In all FLG-deficient skin biopsies, we observed a normal density of LBs. Yet, many organelles in both single- and double-allele subjects displayed microvesicular or amorphous internal contents (Figure 6). In parallel to this abnormality in LB contents, foci of nonlamellar, vesicular contents appeared at the SG-SC interface (Figure 6, A and B). Yet, quantitative studies showed only a minimal abnormality in lamellar body secretion, limited to homozygote subjects, which did not achieve statistical significance (see Supplemental Figure S3A at $h$ ttp://ajp.amjpathol.org).

\section{Nonuniform Extracellular Dispersion of Secreted Contents}

To further address whether the LB abnormality could account for the extracellular lipid abnormalities, we next assessed the postsecretory, subcellular distribution of acidic lipase activity (see Supplemental Figure S3 at $h t t p: / /$ ajp.amjpathol.org), an ultrastructural marker of LB con- tents/secretion. ${ }^{70}$ In normal epidermis, lipid hydrolases, such as acid lipase, are concentrated initially within lamellar bodies, and then secreted in toto, followed by their uniform dispersion within the SC interstices (see Supplemental Figure S3B at $h$ ttp://ajp.amjpathol.org). Although both total contents and secretion of hydrolase activity to the SC interstices appeared near-normal in all IV subjects, enzyme activity was distributed nonuniformly within the SC interstices (see Supplemental Figure S3, C and D, and Supplemental Table S2 at $h$ ttp://ajp.amjpathol.org). Thus, the abnormalities in extracellular lamellar bilayer structure in IV likely reflect impaired loading of secretory cargo within LBs, followed by faulty, postsecretory dispersion of organelle contents.

\section{Additional Mechanisms for the Permeability Barrier Abnormality in IV}

FLG proteolysis regulates SC hydration, ${ }^{71}$ and likely also contributes to the acidification of normal SC. ${ }^{72,73}$ Accordingly, SC hydration declined by about $30 \%$ in doubleallele IV subjects in comparison to wild-type controls (Figure 2D), but reductions in hydration levels did not achieve statistical significance in single-allele subjects. By steepening the gradient of water loss across the SC, decreased SC hydration alone likely also places further stress on the permeability barrier in IV. Decreased SC hydration correlated with the development of a sparse inflammatory infiltrate in double-allele subjects, which was enriched in mast cells (data not shown). Prior studies have shown that prolonged exposure of normal skin to reduced environmental humidity stimulates mast cell infiltration. ${ }^{74}$

Furthermore, we observed an inverse relationship between FLG gene dose and skin surface pH in all FLGdeficient patients, with double-allele subjects displaying

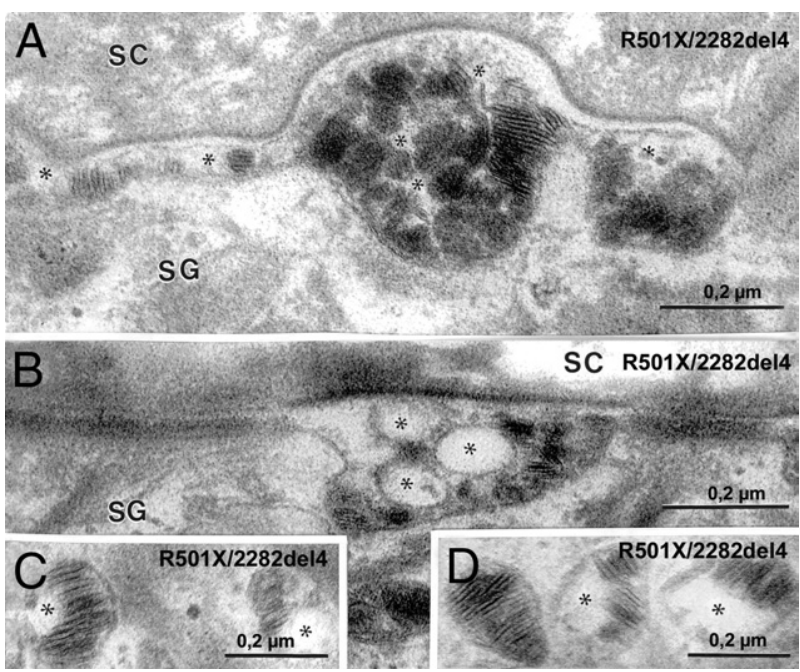

Figure 6. Defective lamellar body (LB) contents in LB secretory system in two double-allele IV subjects (both are compound heterozygote for the same FLG mutations). A and B: Nonlamellar (vesicular) contents at the SG-SC interface (asterisks). C and D: Nonlamellar (vesicular) contents (asterisks) in single LBs, suggesting defective loading of organelle contents. SC, stratum corneum; SG, stratum granulosum. Osmium tetroxide postfixation. Scale bars $=0.2 \mu \mathrm{m}$. 

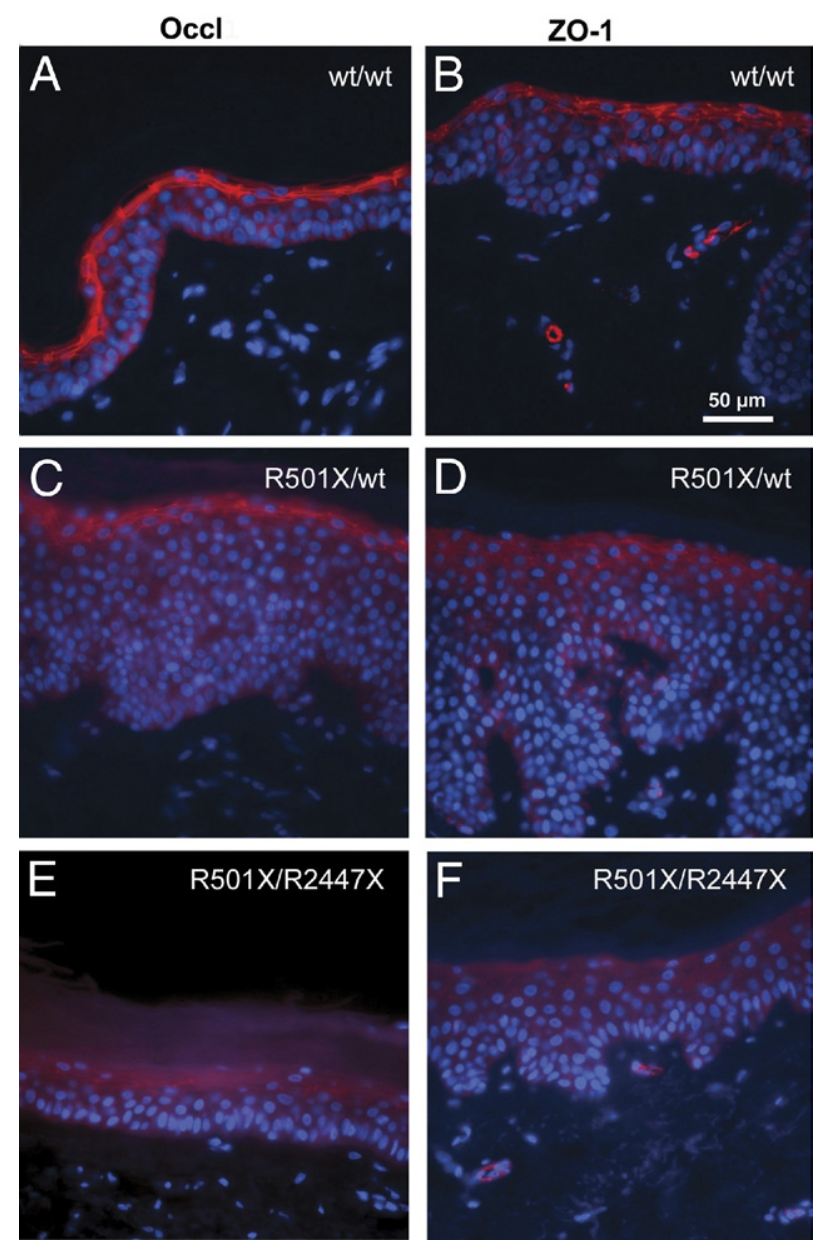

Figure 7. Abnormalities in TJ protein expression in FLG-deficient epidermis shown by immunofluorescence staining for occludin $(\mathbf{A}, \mathbf{C}$, and $\mathbf{E})$ and ZO-1 $(\mathbf{B}, \mathbf{D}$, and $\mathbf{F})$. $\mathbf{A}$ and $\mathbf{B}$ : In control skin, a clear staining at the cell-cell borders of the uppermost living layers is observed for both occludin and ZO-1 (red) C and D: Reduced staining with increased cytoplasmic staining in heterozygous skin biopsies. E and F: Staining is almost completely lost in FLGdeficient skin. The nuclei are stained with DAPI (blue). Overlay of the epifluorescence pictures. Scale bar $=50 \mu \mathrm{m}$.

the greatest elevations in skin surface $\mathrm{pH}$ (Figure 2E). This increase in skin surface $\mathrm{pH}$ could reduce the activity of ceramide-generating hydrolases, ${ }^{55,75}$ accounting for the observed delay in maturation of extracellular lamellar bilayers in IV (Figure 5, D and E). The increased pH in FLGdeficient SC could also impact SC function by altering TJ function and by favoring corneodesmosome proteolysis, which could further compromise barrier function. ${ }^{33}$ Therefore, we assessed the expression and localization of $\mathrm{TJ}$ proteins in FLG-deficient skin biopsies compared to wildtype and heterozygous skin. Whereas in control skin, a clear staining at the cell-cell borders of the uppermost living layers was observed for both occludin and ZO-1 (Figure 7 , $A$ and $B$ ), staining was reduced with a more cytoplasmic pattern in heterozygous skin biopsies (Figure 7, C and D) and was almost completely lost in FLG-deficient skin (Figure 7, E and F). These results indicate an impaired TJ formation in FLG-deficient skin.

Finally, we measured the amount of protein removed per strip by sequential tape stripping, which defines $\mathrm{SC}$ cohesion. ${ }^{76} \mathrm{SC}$ cohesion was markedly abnormal in individuals with two mutations, but only minimally abnormal in single-allele subjects (Figure 2F). Because $\mathrm{SC}$ cohesion depends on corneodesmosome structure, we assessed the structure, density, and distribution (persistence) of corneodesmosomes in FLG-deficient epidermis. Although the structure of individual corneodesmosomes did not differ in single- and double-allele subjects, the density of corneodesmosomes per unit length of $\mathrm{CE}$ differed significantly among FLG-deficient and control subgroups (see Supplemental Figure S2B at $h t t p: / / a j p$. amjpathol.org). Since corneodesmosome structure appeared normal, it is likely that the nonuniform distribution of hydrolase activity (see Supplemental Figure S3 at http://ajp.amjpathol.org) contributes to the overall decrease in corneodesmosome density and defective SC cohesion in IV.

\section{Discussion}

The discovery of FLG mutations in IV has triggered substantial interest in the role of this protein in epidermal barrier function. FLG mutations have been suggested to cause impaired skin barrier function. It is generally accepted that decreased FLG expression results in a leaky skin barrier that then allows ingress of allergens through the epidermis. Disruption of the epidermal barrier skews the cutaneous cytokine milieu toward a Th2 pattern. ${ }^{26-29,77-79}$ However, since Th2 inflammation itself down-regulates FLG expression, ${ }^{25}$ as well as expression of several other epidermal proteins of importance for the barrier, ${ }^{23}$ it remains unknown how FLG mutations alter skin barrier function. To determine the impact and mechanisms whereby FLG deficiency compromises permeability barrier structure and function, we studied here a cohort of IV patients largely devoid of clinical signs of cutaneous inflammation. Although we assessed common FLG variants in this study, we did not employ a comprehensive sequencing strategy, and variations in the number of FLG repeat units were not considered. The genetic studies in this cohort focused on common FLG mutations that correlated well with phenotype severity, making the presence of unrecognized additional mutations unlikely.

Since FLG is a component of the CE, ${ }^{37-39}$ it is not surprising that CEs are attenuated in IV (Figure 3). Yet, the CE alterations reported here do not appear to solely account for the extracellular alterations in lamellar bilayer morphology. We also found that FLG mutations confer alterations in keratin intermediate filament organization that result in a distinctive cytoskeletal abnormality; ie, perinuclear keratin retractions (ie, halos) in granular cells in IV (Figure 1). These observations are consistent with the known role of FLG in keratin intermediate filament aggregation. ${ }^{40,80}$ Although the role for FLG in intermediate filament aggregation in IV has been disputed, ${ }^{81}$ FLG mutation testing was unavailable at that time. Moreover, keratin intermediate filament integrity, assessed by susceptibility to urea extraction, remains unchanged in the organotypic, siRNA knock-down cultures that we used in these studies. ${ }^{53}$ This could be because low amounts of filaggrin are sufficient to aggregate keratin filaments, as 


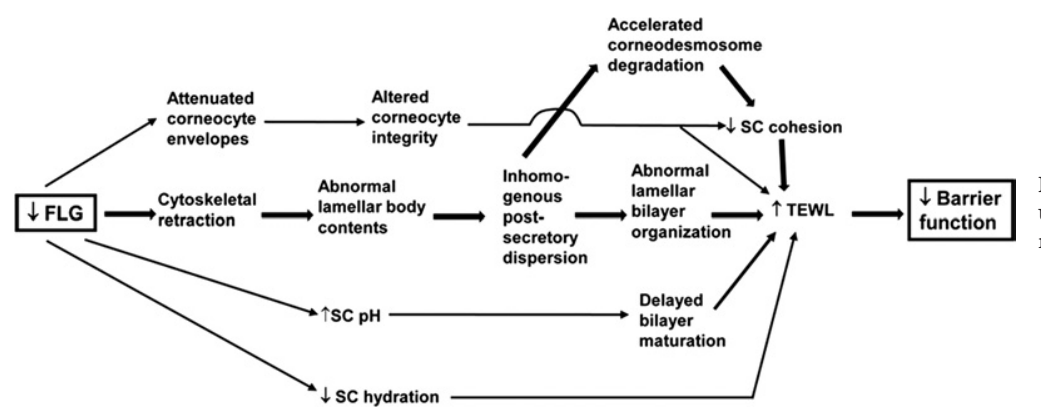

Figure 8. Basis for the barrier abnormality in IV. The two upper rows indicate structural alterations, whereas the lower rows indicate pathways for functional alterations.

seen previously in IV, or because other filaggrin-like proteins present in the epidermis can replace the keratin binding function of filaggrin. Yet, on an ultrastructural level, the same perinuclear retraction halos are present in these cultures as in FLG-deficient subjects (data not shown). Nevertheless, additional evidence is needed to prove the specificity of this finding.

We observed a paracellular, rather than a transcellular, epidermal barrier abnormality in FLG-deficient SC. Although these alterations could be due to an altered lipid composition of FLG-deficient SC, epidermal lipid profiles in IV in the absence of skin inflammation have not yet been assessed, and in organotypic siRNA knock-down cultures, epidermal lipid profiles reportedly are unchanged. ${ }^{53}$ Thus, the extracellular lipid abnormalities in IV likely are due to altered lipid organization rather than to altered lipid composition. As we show here, defective lamellar bilayer structure appears to result from altered loading of lamellar body contents, with defective, postsecretory lipid processing and organization (Figure 8). However, the functional differences between patients and controls were small (Figure 2). This is in concordance with earlier reports in human subjects ${ }^{41,45}$ and with data from animal models. ${ }^{26-29}$ In the latter, permeability was increased for exogenous chemicals such as allergens despite functional differences being small. For ethical reasons, it is difficult to subject IV patients to allergens and to assess thresholds for AD-like skin inflammation. Recently, it was shown by Moniaga et al that Flg-deficient mouse skin shows increased susceptibility to Dermatophagoides pteronyssinus-induced dermatitis, a pathogen relevant for human AD pathogenesis. ${ }^{29}$ There may be different thresholds for movement of water versus other chemicals through the stratum corneum, eg, depending on lipophilicity.

Mechanisms contributing to the paracellular barrier abnormality in IV include the well-known decrease in SC hydration and the increase in skin surface $\mathrm{pH}$ noted here and previously. ${ }^{82}$ As noted above, pro-FLG is processed into filaggrin during the abrupt transition from the granular layer into SC, and further proteolytically degraded into amino acids, which are further deiminated into polycarboxylic acids, such as pyrrolidone carboxylic acid and trans-urocanic acid. These metabolites, in turn, act as osmolytes, drawing water into corneocytes, thereby accounting in large part for corneocyte hydration. Hence, the most immediate result of FLG deficiency in IV is decreased SC hydration, leading in turn to a steeper water gradient across the SC, which likely further "drives" increased transcutaneous water loss.

Decreased presence of FLG products (particularly amino acids) likely accounts for the increase in skin surface $\mathrm{pH}$ in IV (Figure 2E), and this increase could alter the activities of multiple enzymes in the SC. Specifically, the increase in $\mathrm{pH}$ should decrease activities of ceramidegenerating hydrolases, important for extracellular lipid organization. ${ }^{55,75}$ Two of these hydrolytic enzymes exhibit acidic $\mathrm{pH}$ optima [ $\beta$-glucocerebrosidase ( $\beta$-GlcCer'ase) and acid sphingomyelinase (aSMase)], whereas two others [group 1 secretory phospholipase $A_{2}\left(S_{P L A}\right)$ and steroid sulfatase (SSase)], display neutral-to-alkaline $\mathrm{pH}$ optima, suggesting that the altered $\mathrm{pH}$ gradient in IV could account for the observed delay in lipid processing in IV. In addition, decreased generation of acidic FLG products could account for the observed decrease in corneodesmosome density, if serine proteases are inhomogenously activated. ${ }^{83,84}$

In summary, corneocyte defects and abnormalities in extracellular lipid organization together with decreased TJ protein expression and corneodesmosome degradation account for the functional permeability barrier impairment in IV, likely providing the link to the frequent superimposition of $A D$ in these subjects.

\section{Acknowledgments}

Ms. Joan Wakefield and Ms. Janet Gschnitzer provided invaluable assistance with illustrations, editing, and manuscript preparation. We thank Drs. Mao-Qiang Man, Theodora M. Mauro and Kenneth R. Feingold for valuable discussions.

\section{References}

1. Anton-Lamprecht I, Hofbauer M: Ultrastructural distinction of autosomal dominant ichthyosis vulgaris and $\mathrm{X}$-linked recessive ichthyosis. Humangenetik 1972, 15:261-264

2. Fleckman P, Brumbaugh S: Absence of the granular layer and keratohyalin define a morphologically distinct subset of individuals with ichthyosis vulgaris. Exp Dermatol 2002, 11:327-336

3. Nirunsuksiri W, Zhang SH, Fleckman P: Reduced stability and biallelic, coequal expression of profilaggrin mRNA in keratinocytes cultured from subjects with ichthyosis vulgaris. J Invest Dermatol 1998, 110:854-861

4. Sybert VP, Dale BA, Holbrook KA: Ichthyosis vulgaris: identification of a defect in synthesis of filaggrin correlated with an absence of keratohyaline granules. J Invest Dermatol 1985, 84:191-194 
5. Traupe H, Happle R: [Clinical features and genetics of the ichthyosis vulgaris group]. Fortschr Med 1980, 98:1809-1815

6. Uehara M, Hayashi S: Hyperlinear palms: association with ichthyosis and atopic dermatitis. Arch Dermatol 1981, 117:490-491

7. Mevorah B, Marazzi A, Frenk E: The prevalence of accentuated palmoplantar markings and keratosis pilaris in atopic dermatitis, autosomal dominant ichthyosis and control dermatological patients. $\mathrm{Br} \mathrm{J}$ Dermatol 1985, 112:679-685

8. Nomura T, Sandilands A, Akiyama M, Liao H, Evans AT, Sakai K, Ota M, Sugiura H, Yamamoto K, Sato H, Palmer CN, Smith FJ, McLean $\mathrm{WH}$, Shimizu H: Unique mutations in the filaggrin gene in Japanese patients with ichthyosis vulgaris and atopic dermatitis. J Allergy Clin Immunol 2007, 119:434-440

9. Smith FJ, Irvine AD, Terron-Kwiatkowski A, Sandilands A, Campbel LE, Zhao Y, Liao H, Evans AT, Goudie DR, Lewis-Jones S, Arseculeratne G, Munro CS, Sergeant A, O'Regan G, Bale SJ, Compton JG. DiGiovanna JJ, Presland RB, Fleckman P, McLean WH: Loss-offunction mutations in the gene encoding filaggrin cause ichthyosis vulgaris. Nat Genet 2006, 38:337-342

10. Sandilands A, O'Regan GM, Liao H, Zhao Y, Terron-Kwiatkowski A, Watson RM, Cassidy AJ, Goudie DR, Smith FJ, McLean WH, Irvine $A D$ : Prevalent and rare mutations in the gene encoding filaggrin cause ichthyosis vulgaris and predispose individuals to atopic dermatitis. J Invest Dermatol 2006, 126:1770-1775

11. Gruber R, Janecke AR, Fauth C, Utermann G, Fritsch PO, Schmuth M: Filaggrin mutations p.R501X and c. 2282del4 in ichthyosis vulgaris. Eur J Hum Genet 2007, 15:179-184

12. Sandilands A, Terron-Kwiatkowski A, Hull PR, O'Regan GM, Clayton TH, Watson RM, Carrick T, Evans AT, Liao H, Zhao Y, Campbell LE, Schmuth M, Gruber R, Janecke AR, Elias PM, van Steensel MA, Nagtzaam I, van Geel M, Steiilen PM, Munro CS, Bradley DG, Palmer CN, Smith FJ, McLean WH, Irvine AD: Comprehensive analysis of the gene encoding filaggrin uncovers prevalent and rare mutations in ichthyosis vulgaris and atopic eczema. Nat Genet 2007, 39:650-654

13. Palmer CN, Irvine AD, Terron-Kwiatkowski A, Zhao Y, Liao H, Lee SP, Goudie DR, Sandilands A, Campbell LE, Smith FJ, O'Regan GM, Watson RM, Cecil JE, Bale SJ, Compton JG, DiGiovanna JJ, Fleckman P, Lewis-Jones S, Arseculeratne G, Sergeant A, Munro CS, El Houate B, McElreavey K, Halkjaer LB, Bisgaard H, Mukhopadhyay S, McLean WH: Common loss-of-function variants of the epidermal barrier protein filaggrin are a major predisposing factor for atopic dermatitis. Nat Genet 2006, 38:441-446

14. Weidinger S, Illig T, Baurecht $\mathrm{H}$, Irvine AD, Rodriguez E, Diaz-Lacava A, Klopp N, Wagenpfeil S, Zhao Y, Liao H, Lee SP, Palmer CN, Jenneck C, Maintz L, Hagemann T, Behrendt H, Ring J, Nothen MM, McLean WH, Novak N: Loss-of-function variations within the filaggrin gene predispose for atopic dermatitis with allergic sensitizations. $J$ Allergy Clin Immunol 2006, 118:214-219

15. Hubiche T, Ged C, Benard A, Leaute-Labreze C, McElreavey K, de Verneuil H, Taieb A, Boralevi F: Analysis of SPINK 5. KLK 7 and FLG genotypes in a French atopic dermatitis cohort Acta Derm Venereol 2007, 87:499-505

16. Sandilands A, Smith FJ, Irvine AD, McLean WH: Filaggrin's fuller figure: a glimpse into the genetic architecture of atopic dermatitis. J Invest Dermatol 2007, 127:1282-1284

17. Oji V, Seller N, Sandilands A, Gruber R, Gerss J, Huffmeier U, Hamm H, Emmert S, Aufenvenne K, Metze D, Luger T, Loser K, Hausser I, Traupe H, McLean WH: Ichthyosis vulgaris: novel FLG mutations in the German population and high presence of CD1a+ cells in the epidermis of the atopic subgroup. Br J Dermatol 2009, 160:771-781

18. Kezic S, Kemperman PM, Koster ES, de Jongh CM, Thio HB, Campbell LE, Irvine AD, McLean WH, Puppels GJ, Caspers PJ: Loss-offunction mutations in the filaggrin gene lead to reduced level of natural moisturizing factor in the stratum corneum. $J$ Invest Dermatol 2008, 128:2117-2119

19. Hudson TJ: Skin barrier function and allergic risk. Nat Genet 2006, 38:399-400

20. McGrath JA: Filaggrin and the great epidermal barrier grief. Australas J Dermatol 2008, 49:67-73; quiz 73-64

21. Rodriguez E, Illig T, Weidinger S: Filaggrin loss-of-function mutations and association with allergic diseases. Pharmacogenomics 2008, 9:399-413

22. Segre JA: Epidermal barrier formation and recovery in skin disorders. $\mathrm{J}$ Clin Invest 2006, 116:1150-1158
23. Elias PM, Hatano Y, Williams ML: Basis for the barrier abnormality in atopic dermatitis: outside-inside-outside pathogenic mechanisms. $J$ Allergy Clin Immunol 2008, 121:1337-1343

24. Proksch E, Brandner JM, Jensen JM: The skin: an indispensable barrier. Exp Dermatol 2008, 17:1063-1072

25. Howell MD, Kim BE, Gao P, Grant AV, Boguniewicz M, Debenedetto A, Schneider L, Beck LA, Barnes KC, Leung DY: Cytokine modulation of atopic dermatitis filaggrin skin expression. J Allergy Clin Immunol 2007, 120:150-155

26. Fallon PG, Sasaki T, Sandilands A, Campbell LE, Saunders SP, Mangan NE, Callanan JJ, Kawasaki H, Shiohama A, Kubo A, Sundberg JP, Presland RB, Fleckman P, Shimizu N, Kudoh J, Irvine AD, Amagai M, McLean WH: A homozygous frameshift mutation in the mouse Flg gene facilitates enhanced percutaneous allergen priming. Nat Genet 2009, 41:602-608

27. Scharschmidt TC, Man MQ, Hatano Y, Crumrine D, Gunathilake R, Sundberg JP, Silva KA, Mauro TM, Hupe M, Cho S, Wu Y, Celli A, Schmuth M, Feingold KR, Elias PM: Filaggrin deficiency confers a paracellular barrier abnormality that reduces inflammatory thresholds to irritants and haptens. J Allergy Clin Immunol 2009, 124:496-506, 506 e $491-496$

28. Oyoshi MK, Murphy GF, Geha RS: Filaggrin-deficient mice exhibit TH17-dominated skin inflammation and permissiveness to epicutaneous sensitization with protein antigen. J Allergy Clin Immunol 2009, 124:485-493, 493 e481

29. Moniaga CS, Egawa G, Kawasaki H, Hara-Chikuma M, Honda T, Tanizaki H, Nakajima S, Otsuka A, Matsuoka H, Kubo A, Sakabe J, Tokura Y, Miyachi Y, Amagai M, Kabashima K: Flaky tail mouse denotes human atopic dermatitis in the steady state and by topical application with Dermatophagoides pteronyssinus extract. Am J Pathol 2010, 176:2385-2393

30. Elias PM: Stratum corneum defensive functions: an integrated view. J Invest Dermatol 2005, 125:183-200

31. Elias PM: The skin barrier as an innate immune element. Semin Immunopathol 2007, 29:3-14

32. Feingold KR, Schmuth M, Elias PM: The regulation of permeability barrier homeostasis. J Invest Dermatol 2007, 127:1574-1576

33. Cork MJ, Danby SG, Vasilopoulos Y, Hadgraft J, Lane ME, Moustafa M, Guy RH, Macgowan AL, Tazi-Ahnini R, Ward SJ: Epidermal barrier dysfunction in atopic dermatitis. J Invest Dermatol 2009, 129:1892-1908

34. Elias PM, Schmuth M, Uchida $Y$, Rice RH, Behne M, Crumrine D, Feingold KR, Holleran WM: Basis for the permeability barrier abnormality in lamellar ichthyosis. Exp Dermatol 2002, 11:248-256

35. Schmuth M, Fluhr JW, Crumrine DC, Uchida Y, Hachem JP, Behne M, Moskowitz DG, Christiano AM, Feingold KR, Elias PM: Structural and functional consequences of loricrin mutations in human loricrin keratoderma (Vohwinkel syndrome with ichthyosis). J Invest Dermatol 2004, 122:909-922

36. Schmuth M, Yosipovitch G, Williams ML, Weber F, Hintner H, OrtizUrda S, Rappersberger K, Crumrine D, Feingold KR, Elias PM: Pathogenesis of the permeability barrier abnormality in epidermolytic hyperkeratosis. J Invest Dermatol 2001, 117:837-847

37. Takahashi M, Tezuka T, Katunuma N: Filaggrin linker segment peptide and cystatin alpha are parts of a complex of the cornified envelope of epidermis. Arch Biochem Biophys 1996, 329:123-126

38. Steinert PM, Marekov LN: The proteins elafin, filaggrin, keratin intermediate filaments, loricrin, and small proline-rich proteins 1 and 2 are isodipeptide cross-linked components of the human epidermal cornified cell envelope. J Biol Chem 1995, 270:17702-17711

39. Simon M, Haftek M, Sebbag M, Montezin M, Girbal-Neuhauser E, Schmitt D, Serre G: Evidence that filaggrin is a component of cornified cell envelopes in human plantar epidermis. Biochem J 1996, 317 (Pt 1):173-177

40. Dale BA, Presland RB, Lewis SP, Underwood RA, Fleckman P: Transient expression of epidermal filaggrin in cultured cells causes collapse of intermediate filament networks with alteration of cell shape and nuclear integrity. J Invest Dermatol 1997, 108:179-187

41. Lavrijsen AP, Oestmann E, Hermans J, Bodde HE, Vermeer BJ, Ponec M: Barrier function parameters in various keratinization disorders: transepidermal water loss and vascular response to hexyl nicotinate. Br J Dermatol 1993, 129:547-553

42. Frost $P$, Weinstein GD, Bothwell JW, Wildnauer R: Ichthyosiform dermatoses. 3. Studies of transepidermal water loss Arch Dermatol 1968, 98:230-233 
43. Abe T, Ohkido M, Yamamoto K: Studies on skin surface barrier functions: skin surface lipids and transepidermal water loss in atopic skin during childhood. J Dermatol 1978, 5:223-229

44. Werner $Y$, Lindberg $M$ : Transepidermal water loss in dry and clinically normal skin in patients with atopic dermatitis. Acta Derm Venereol 1985, 65:102-105

45. Fartasch M, Diepgen TL: The barrier function in atopic dry skin. Disturbance of membrane-coating granule exocytosis and formation of epidermal lipids? Acta Derm Venereol Suppl (Stockh) 1992, 176:26-31

46. Pinnagoda J, Tupker RA, Agner T, Serup J: Guidelines for transepidermal water loss (TEWL) measurement. A report from the Standardization Group of the European Society of Contact Dermatitis. Contact Dermatitis 1990, 22:164-178

47. Nyren M, Hagstromer L, Emtestam L: On assessment of skin reactivity using electrical impedance. Ann N Y Acad Sci 1999, 873:214-220

48. Parra JL, Paye M: EEMCO guidance for the in vivo assessment of skin surface pH. Skin Pharmacol Appl Skin Physiol 2003, 16:188-202

49. Määttä A, DiColandrea T, Groot K, Watt FM: Gene targeting of envoplakin, a cytoskeletal linker protein and precursor of the epiderma cornified envelope. Mol Cell Biol 2001, 21:7047-7053

50. Jeon S, Djian P, Green H: Inability of keratinocytes lacking their specific transglutaminase to form cross-linked envelopes: absence of envelopes as a simple diagnostic test for lamellar ichthyosis. Proc Natl Acad Sci U S A: 1998, 95:687-690

51. Dreher F, Arens A, Hostynek JJ, Mudumba S, Ademola J, Maibach $\mathrm{HI}$ : Colorimetric method for quantifying human Stratum corneum removed by adhesive-tape stripping. Acta Derm Venereol 1998, 78: $186-189$

52. Mildner M, Ballaun C, Stichenwirth M, Bauer R, Gmeiner R, Buchberger M, Mlitz V, Tschachler E: Gene silencing in a human organotypic skin model. Biochem Biophys Res Commun 2006, 348:76-82

53. Mildner M, Jin J, Eckhart L, Kezic S, Gruber F, Barresi C, Stremnitzer C, Buchberger M, Mlitz V, Ballaun C, Sterniczky B, Fodinger D, Tschachler E: Knockdown of filaggrin impairs diffusion barrier function and increases UV sensitivity in a human skin model. J Invest Dermatol 2010, 130:2286-2294

54. Elias PM, Fartasch M, Crumrine D, Behne M, Uchida Y, Holleran WM: Origin of the corneocyte lipid envelope (CLE): observations in harlequin ichthyosis and cultured human keratinocytes. J Invest Dermatol 2000, 115:765-769

55. Hachem JP, Wagberg F, Schmuth M, Crumrine D, Lissens W, Jayakumar A, Houben E, Mauro TM, Leonardsson G, Brattsand M, Egelrud T, Roseeuw D, Clayman GL, Feingold KR, Williams ML, Elias PM: Serine protease activity and residual LEKTI expression determine phenotype in Netherton syndrome. J Invest Dermatol 2006, 126:1609-1621

56. Demerjian M, Crumrine DA, Milstone LM, Williams ML, Elias PM: Barrier dysfunction and pathogenesis of neutral lipid storage disease with ichthyosis (Chanarin-Dorfman syndrome). J Invest Dermatol 2006, 126:2032-2038

57. Madison KC, Swartzendruber DC, Wertz PW, Downing DT: Lamellar granule extrusion and stratum corneum intercellular lamellae in murine keratinocyte cultures. J Invest Dermatol 1988, 90:110-116

58. Hou SY, Mitra AK, White SH, Menon GK, Ghadially R, Elias PM: Membrane structures in normal and essential fatty acid-deficient stratum corneum: characterization by ruthenium tetroxide staining and X-ray diffraction. J Invest Dermatol 1991, 96:215-223

59. Rassner UA, Crumrine DA, Nau P, Elias PM: Microwave incubation improves lipolytic enzyme preservation for ultrastructural cytochemistry. Histochem J: 1997, 29:387-392

60. Elias PM, Ghadially R: The aged epidermal permeability barrier: basis for functional abnormalities. Clin Geriatr Med 2002, 18:103-120, vii

61. Elias PM: Stratum corneum architecture, metabolic activity and interactivity with subjacent cell layers. Exp Dermatol 1996, 5:191-201

62. Williams ML, Elias PM: Stratum corneum lipids in disorders of cornification: increased cholesterol sulfate content of stratum corneum in recessive $\mathrm{x}$-linked ichthyosis. J Clin Invest 1981, 68:14041410

63. Elias PM, Fritsch PO, Lampe M, Williams ML, Brown BE, Nemanic M, Grayson S: Retinoid effects on epidermal structure, differentiation, and permeability. Lab Invest 1981, 44:531-540

64. Elias P, Ahn S, Brown B, Crumrine D, Feingold KR: Origin of the epidermal calcium gradient: regulation by barrier status and role of active vs passive mechanisms. J Invest Dermatol 2002, 119:1269-1274
65. Menon GK, Elias PM, Lee SH, Feingold KR: Localization of calcium in murine epidermis following disruption and repair of the permeability barrier. Cell Tissue Res 1992, 270:503-512

66. Elias PM, Nau P, Hanley K, Cullander C, Crumrine D, Bench G, Sideras-Haddad E, Mauro T, Williams ML, Feingold KR: Formation of the epidermal calcium gradient coincides with key milestones of barrier ontogenesis in the rodent. J Invest Dermatol 1998, 110: 399-404

67. Menon GK, Grayson S, Elias PM: Cytochemical and biochemical localization of lipase and sphingomyelinase activity in mammalian epidermis. J Invest Dermatol 1986, 86:591-597

68. Rice $\mathrm{RH}$, Crumrine D, Uchida Y, Gruber R, Elias PM: Structural changes in epidermal scale and appendages as indicators of defective TGM1 activity. Arch Dermatol Res 2005, 297:127-133

69. Schmuth M, Gruber R, Elias PM, Williams ML: Ichthyosis update: towards a function-driven model of pathogenesis of the disorders of cornification and the role of corneocyte proteins in these disorders. Adv Dermatol 2007, 23:231-256

70. Menon GK, Price LF, Bommannan B, Elias PM, Feingold KR: Selective obliteration of the epidermal calcium gradient leads to enhanced lamellar body secretion. J Invest Dermatol 1994, 102:789-795

71. Scott IR, Harding CR: Filaggrin breakdown to water binding compounds during development of the rat stratum corneum is controlled by the water activity of the environment. Dev Biol 1986, 115:84-92

72. Krien PM, Kermici M: Evidence for the existence of a self-regulated enzymatic process within the human stratum corneum -an unexpected role for urocanic acid. J Invest Dermatol 2000, 115:414-420

73. Fluhr JW, Elias PM, Man MQ, Hupe M, Selden C, Sundberg JP, Tschachler E, Eckhart L, Mauro TM, Feingold KR: Is the filaggrinhistidine-urocanic acid pathway essential for stratum corneum acidification? J Invest Dermatol 2010, 130:2141-2144

74. Denda M, Sato J, Tsuchiya T, Elias PM, Feingold KR: Low humidity stimulates epidermal DNA synthesis and amplifies the hyperproliferative response to barrier disruption: implication for seasonal exacerbations of inflammatory dermatoses. J Invest Dermatol 1998, 111: 873-878

75. Hachem JP, Man MQ, Crumrine D, Uchida Y, Brown BE, Rogiers V, Roseeuw D, Feingold KR, Elias PM: Sustained serine proteases activity by prolonged increase in $\mathrm{pH}$ leads to degradation of lipid processing enzymes and profound alterations of barrier function and stratum corneum integrity. J Invest Dermatol 2005, 125:510-520

76. Fluhr JW, Kao J, Jain M, Ahn SK, Feingold KR, Elias PM: Generation of free fatty acids from phospholipids regulates stratum corneum acidification and integrity. J Invest Dermatol 2001, 117:44-51

77. Nishijima T, Tokura Y, Imokawa G, Seo N, Furukawa F, Takigawa M: Altered permeability and disordered cutaneous immunoregulatory function in mice with acute barrier disruption. J Invest Dermatol 1997, 109:175-182

78. Kondo H, Ichikawa $\mathrm{Y}$, Imokawa G: Percutaneous sensitization with allergens through barrier-disrupted skin elicits a Th2-dominant cytokine response. Eur J Immunol 1998, 28:769-779

79. Onoue A, Kabashima K, Kobayashi M, Mori T, Tokura Y: Induction of eosinophil- and Th2-attracting epidermal chemokines and cutaneous late-phase reaction in tape-stripped skin. Exp Dermatol 2009, 18 1036-1043

80. Steinert PM, Cantieri JS, Teller DC, Lonsdale-Eccles JD, Dale BA: Characterization of a class of cationic proteins that specifically interact with intermediate filaments. Proc Natl Acad Sci U S A: 1981 , 78:4097-4101

81. Weidenthaler B, Hausser I, Anton-Lamprecht I: Is filaggrin really a filament-aggregating protein in vivo? Arch Dermatol Res 1993, 285 : $111-120$

82. Ohman $H$, Vahlquist $A$ : The $\mathrm{pH}$ gradient over the stratum corneum differs in $\mathrm{X}$-linked recessive and autosomal dominant ichthyosis: a clue to the molecular origin of the "acid skin mantle"? J Invest Dermatol 1998, 111:674-677

83. Johnson B, Horn T, Sander C, Kohler S, Smoller BR: Expression of stratum corneum chymotryptic enzyme in ichthyoses and squamoproliferative processes. J Cutan Pathol 2003, 30:358-362

84. Elsayed-Ali H, Barton S, Marks R: Stereological studies of desmosomes in ichthyosis vulgaris. Br J Dermatol 1992, 126:24-28 